\title{
PERAN BRAND “KAMPOENG BATIK LAWEYAN"DALAM MENGUATKAN BATIK LAWEYAN UNTUK MENINGKATKAN DAYA SAING INDUSTRI BATIK "KAMPOENG BATIK LAWEYAN" SOLO
}

\author{
Basworo Dibyo ${ }^{1}$, Sujadi ${ }^{2}$ \\ FakultasEkonomidanBisnis, UniversitasMuhammadiyah Surakarta \\ Email : Basworo.Dibyo@ums.ac.id,Sujadi@ums.ac.id
}

\begin{abstract}
Abstrak. Keberadaan Batik Laweyan sudah sejak sebelum tahun 1500M (Mlayadipuro, 1984), dengan Pasar Laweyan dan Bandar Kabanarannya merupakan pusat perdagangan dan penjualan bahan sandang (lawe) Kerajaan Pajang yang ramai dan strategis pada kala itu (Priyatmono, 2004). Kunjungan ke Laweyan membuktikan Laweyan merupakan daerah perbatikan yang telah ada sejak dulu, dapat dilihat dari bentuk bangunan di daerah tersebut (Aviarini Indrati, dkk, 2011). Kebijakan pemerintah Kota Surakarta menetapkan Kampoeng Laweyan sebagai kawasan pariwisata dengan nama "Kampoeng Batik Laweyan", dan kewajiban Pegawai Negeri Sipil berbusana batik pada saat tertentu menjadikan perkembangan industri batik di Laweyan sangat bagus (Atiqa Sabardila, dkk, 2008). Pengusaha di "Kampoeng Batik Laweyan" sebenarnya sudah mampu melakukan ekspor ke manca Negara, khususnya di Asia, Eropa, Timur Tengah dan Amerika. Namun sebagian besar masih merupakan produk tanpa merk, sehingga belum adanya peningkatan daya saing produk untuk masuk pasar internasional dengan merk lokal. (Siti Rahayu Binarsih, dkk, 2013). Brand Kampoeng Batik Laweyan, dengan dukungan teknologi sekarang ini, menjadikan adanya situs "Kampoeng Batik Laweyan", selain dapat memperluas wilayah pemasaran produk, juga semakin memudahkan calon pembeli. Data dalam penelitian ini diambil dari semua pengusaha batik di "Kampoeng Batik Laweyan”yang berjumlah 56 pengusaha dengan menggunakan kuesioner yang sudah lolos uji validitas dan reliablitas. Setelah lolos uji asumsi klasik meliputi uji multikolinearitas, uji autokorelasi, uji heteroskedastisitas dan uji normalitas, kemudian dilakukan Analisis regresi berganda dan regresi dengan moderasi diperoleh hasil : 1) Variabel Produk Batik Laweyan Signifikan Mempengaruhi Peningkatan Daya Saing Industri Batik "Kampoeng Batik Laweyan" di Kota Solo, 2) Brand "Kampoeng Batik Laweyan" Signifikan Berpengaruh terhadap Peningkatan Daya Saing Industri Batik Kampoeng Batik Laweyan di Kota Solo, 3) Brand "Kampoeng Batik Laweyan" Signifikan Menguatkan Pengaruh Batik Laweyan dalam Peningkatkan Daya Saing Industri Batik "Kampoeng Batik Laweyan" Solo, sehingga ketiga hipotesis terbukti kebenarannya. Hasil penelitian ini dapat digunakan sebagai acuan dalam menetapkan kebijakan tentang pengembangan "Kampung Batik Laweyan", maka sangat perlu dilakukan penelitian untuk mempertajam peran merk (cluster branding) terhadap daya saing industri batik baik dalam pasar nasional maupun pasar global.
\end{abstract}

Kata Kunci: Kampoeng Batik Laweyan, Brand, Batik, Laweyan.

Abstract. The existence of Laweyan Batik has been around since before 1500M (Mlayadipuro, 1984), with Laweyan Market and Bandar Kabanaran as a center of trade and sell of clothing material (lawe) of Pajang Kingdom which is busy and strategic at that time (Priyatmono, 2004). A visit to Laweyan proves that Laweyan is a batik area that has existed long ago, it can be seen from the form of buildings in the area (Aviarini Indrati, et al, 2011). The policy of Surakarta City Government has established Kampoeng Laweyan as a tourism area under the name of "Kampoeng Batik Laweyan", and the obligation of Civil Servant in wearing batik dress at certain time made the development of batik industry in Laweyan very good (Atiqa Sabardila, et al, 2008). Entrepreneurs in "Kampoeng Batik Laweyan" actually have been able to export to foreign countries, especially in Asia, Europe, Middle East and America. But most of them are still product without brand, so there is no increase in product competitiveness to enter international market with local brand. (Siti Rahayu Binarsih, et al, 2013). Brand Kampoeng Batik Laweyan, with the support of technology today, makes the site "Kampoeng Batik Laweyan" exists, in addition to expand the marketing area of the product, it also make easier for prospective of buyers. The data in this study were taken from all batik entrepreneurs in "Kampoeng Batik Laweyan" which amounted to 56 entrepreneurs by using questionnaires that have passed the validity and reliablitas test. After passed the classic assumption test 
include multicollinearity test, autocorrelation test, heteroscedasticity test and normality test, then multiple regression analysis and regression with moderation obtained result: 1) The variable Batik Laweyan Product Significantly Improve the Batik Industry Competitiveness "Kampoeng Batik Laweyan" in Kota Solo, 2) Brand "Kampoeng Batik Laweyan" is Significantly Influence on Improving Competitiveness of Batik in Industry Kampoeng Batik Laweyan in Solo, 3) Brand "Kampoeng Batik Laweyan" Significantly Strengthening the Laweyan Batik Effect in Improving Batik Industry Competitiveness "Kampoeng Batik Laweyan" Solo, So the three hypotheses proved to be true. The results of this study can be used as a reference in establishing policies about the development of "Kampung Batik Laweyan", it is very necessary to conduct research to sharpen the role of the brand (cluster branding) to batik industry competitiveness in both national and global markets.

Keywords: Kampoeng Batik Laweyan, Brand, Batik, Laweyan

\section{LATAR BELAKANG MASALAH}

Keberadaan Batik Laweyan sudah sejak jaman dulu kala sebelum tahun $1500 \mathrm{M}$, Laweyan merupakan suatu kawasan sentra industri batik yang unik, spesifik dan bersejarah (Mlayadipuro, 1984), dengan Pasar Laweyan dan Bandar Kabanarannya merupakan pusat perdagangan dan penjualan bahan sandang (lawe) Kerajaan Pajang yang ramai dan strategis (Priyatmono, 2004). Peruntukan lahan kawasan Kampung Laweyan saat ini didominasi oleh fungsi permukiman, komersial dan kegiatan industri batik yang tergolong peruntukan campuran atau mix use, yaitu untuk permukiman dan kegiatan industri batik terutama di dalam kampung sedangkan untuk penggunaan perdagangan/ komersial mendominasi di ruas Jalan DR. Rajiman. Kondisi tersebut sesuai dengan peruntukan yang ditetapkan pada kawasan ini, yaitu sebagai kawasan industri rumahan (home industry) batik. Pada Pemerintahan Orde Lama mengeluarkan kebijakan program benteng yang bertujuan untuk menumbuhkan kewiraswastaan pribumi. Di bidang perbatikan, menimbulkan efek positif, yaitu pemupukan modal, penyerapan tenaga kerja, peningkatan keterampilan kerja, dan meluasnya industri batik tulis dan cap di berbagai penjuru kota Surakarta (Nurhadiantomo,2004). Pada masa Orde Baru, kebijakan ditujukan mengejar pertumbuhan ekonomi yang mengutamakan pertumbuhan industri garmen dan printing bermotif batik. Terjadi ketimpangan antara produksi manufaktur batik printing dengan produksi pabrikan cap dan industri rumah tangga batik tulis. Persaingan ekonomi komersial secara terus-menerus mengakibatkan batik cap kalah bersaing baik dari segi kualitas maupun harga (Boeke, 1973).

Kebijakan pemerintah Kota Surakarta yang menetapkan Kampoeng Laweyan sebagai kawasan pariwisata, menurut para pembatik menjadikan perkembangan industri batik mereka rasakan cukup bagus, bahkan bagus sekali, apalagi setelah adanya pembajakan dan pematenan batik Indonesia oleh Malaysia. Dukungan lain berupa kewajiban berbusana batik bagi pegawai negeri pada saat tertentu. (Atiqa Sabardila, dkk, 2008). Pengunjung selain datang untuk membeli batik, juga untuk menikmati situs budaya "Kampoeng Batik Laweyan" atau belajar seni membatik (Ridho \& Mukti Ali, 2013). Penelitian lain (Andri Satrio Pratomo, et al , (2006), Ratih K (2011) menunjukkan bahwa Kampung Batik Laweyan memenuhi kriteria sebagai kampung tradisional perkotaan dengan karakter ketradisionalan yang kuat dan mampu mempertahankan karakter ketradisionalannya. Kehidupan serta orientasi nilai masyarakat Laweyan berbeda dengan masyarakat Surakarta pada umumnya (Sarsono dan Suyatno, 1985). Kunjungan ke Laweyan juga membuktikan bahwa Laweyan merupakan daerah perbatikan yang telah ada sejak dulu dengan melihat bentuk bangunan yang ada di daerah tersebut (Aviarini Indrati, dkk, 2011). Sebagai kampung yang memiliki karakteristik berbeda dengan kampung lain di sekitarnya, tentu saja memiliki proses perkembangan yang berbeda (Mitsuo Nakamura, 1983). Secara sosiologis dapat dikatakan bahwa masyarakat Laweyan sebagai inclave society. Keberadaan masyarakat tersebut sangat berbeda dengan komunitas yang lebih besar di sekitarnya (Geertz, 1973), maka untuk mempertahankan komunitasnya, lebih 
banyak tergantung pada masyarakat Laweyan itu sendiri. (Baidi, 2006), menurut Vicka, dkk (diakses 31 Maret 2015), bahwa untuk pengembangan Kampung Batik sangat perlu adanya kerja sama dan pelibatan Masyarakat serta perlunya meningkatkan sarana dan prasarana, juga perlunya karakteristik masyarakat dan dukungan pariwisata agar Kampoeng Batik Laweyan siap menjadi Kawasan Wisata Budaya.

Pada mulanya batik Laweyan didominasi oleh disain batik tradisional. Setelah adanya "Kampoeng Batik Laweyan", motif disain telah jauh berkembang. Karena tuntutan permintaan pasar dan adanya usaha untuk menampilkan karya unik dan khas di masingmasing gerai (khususnya untuk menarik wisatawan), maka muncullah motif baru yaitu motif modern dan abstrak. Menurut Indah Nur Rahmawati (2013) bahwa hobi apabila dikombinasikan dengan jiwa entrepeneurship akan menghasilkan nilai jual, sehingga Produsen Batik di Kampung Batik Laweyan Solo agar memperluas pemasaran batik hasil produksinya. Dari segi diversifikasi produk, sebelumnya produk batik hanya terbatas pada produk sandang, setelah Kampoeng Batik berkembang munculah produk batik dalam bentuk lain seperti kerajinan tangan (tas, dompet dan perlengkapan pakaian), perlengkapan rumah tangga (household), batik kayu, batik kaca. Sebagian besar produksi batik di Laweyan masih menggunakan teknologi tradisional. Teknologi tradisional masih tetap dipertahankan untuk menjaga kekhasan dan keunikan batik Laweyan, inovasi Batik Laweyan meningkatkan daya saing terlihat dari pemasaran Batik Laweyan, tidak hanya di dalam negeri tetapi sampai ke luar negeri (Ridho MS \& Mukti Ali, 2013).

Visi "Kampung Batik Laweyan" adalah menjadikan Laweyan sebagai kawasan pusat industri batik dan heritage yang ramah lingkungan melalui pembangunan yang berkelanjutan. "Kampoeng Batik Laweyan" merupakan daerah yang terdiri dari industri kecil yang memproduksi batik sekaligus menjualnya. Dengan berdirinya "Kampoeng Batik Laweyan", akibat dari adanya interaksi dengan masyarakat luar khususnya masyarakat pers dan usaha untuk bertahan dari persaingan global, maka promosi dilakukan melalui media koran, majalah, televisi, brosur, pameran, baik secara individu dan bersamasama dalam satu komunitas. Di Era globalisasi daya saing UMKM Batik terwujud dengan cara membangun kekuatan bersama dengan digerakkan oleh masing-masing komponen, (Retno Dewanti, dkk, 2013), maka dengan adanya Kampoeng Batik Laweyan maka daya saing akan lebih mudah diwujudkan. Selain itu promosi terhadap "Kampoeng Batik Laweyan" melalui artikel-artikel yang di tulis di blog, facebook. Terdapat Paguyuban "Kampung Batik Laweyan" yang aktif di Website "Kampung Batik Laweyan", dan mengikuti pameran-pameran penjualan batik. Pengusaha di "Kampoeng Batik Laweyan" sesungguhnya sudah mampu melakukan ekspor ke manca Negara, khususnya di Asia, Eropa, Timur Tengah dan Amerika, sebagian besar produk eskpor batik masih merupakan produk tanpa merk, sehingga belum secara maksimal dari sisi peningkatan daya saing produk untuk masuk pasar internasional dengan merk lokal. (Siti Rahayu Binarsih, $\mathrm{dkk}, 2013$ )

\section{Dengan Brand Kampoeng Batik} Laweyan, menjadikan adanya Batik Mark. Batik mark adalah suatu tanda yang menunjukkan identitas dan ciri batik buatan Indonesia yang terdiri dari 3 jenis yaitu batik tulis, batik cap dan batik kombinasi dengan hak cipta No. 034100 tgl 5 juni 2007. Tujuan batik mark adalah 1). Memberikan jaminan mutu batik Indonesia, 2).Melestarikan dan melindungi produk batik Indonesia secara hukum dari berbagai ancaman di bidang HKI maupun perdagangan di dalam negeri maupun internasional. 3). Menciptakan suatu bentuk identitas batik Indonesia agar masyarakat dalam dan luar negeri dapat dengan mudah mengenali produk batik Indonesia. 4).Mendorong peningkatan kepercayaan konsumen terhadap mutu batik Indonesia dan 5) Meningkatkan apresiasi dan citra batik Indonesia di masyarakat internasional. Adapun manfaat Batikmark adalah 1). Memberikan kepastian hukum bagi produsen dan konsumen produk batik Indonesia terhadap keaslian dan mutu produk yang diperdagangkan, 2). Sebagai pembeda antara batik buatan Indonesia dengan batik negara lain, 3). Memudahkan konsumen mancanegara mengenal batik Indonesia, 4). Mendukung promosi batik Indonesia di pasar Internasional, sebagai salah satu pendekatan 
pemasaran untuk menghasilkan keunggulan kompetitif. (Siti Rahayu Binarsih, dkk, 2013).

Pencanangan "Kampoeng Batik Laweyan", dengan dukungan teknologi sekarang ini, menjadikan adanya situs "Kampoeng Batik Laweyan", selain dapat memperluas wilayah pemasaran produk, juga semakin memudahkan calon pembeli. Calon pembeli tidak harus datang ke "Kampoeng Batik Laweyan" karena proses pembayaran pun dapat dilakukan secara online melalui transfer rekening. Barang pesanan selanjutnya akan dikirim ke tempat tujuan.

Dari pemahaman diatas maka peneliti merumuskan masalah sebagai berikut :

1. Apakah Batik Laweyan dengan diferensiasinya mempengaruhi

Peningkatan Daya saing Industri Batik

"Kampoeng Batik Laweyan" Solo?

2. Apakah Penetapan Brand "Kampoeng Batik Laweyan" berpengaruh terhadap Peningkatan Daya Saing Industri Batik "Kampoeng Batik Laweyan" Solo?
3. Apakah Brand "Kampoeng Batik Laweyan" Menguatkan Batik Laweyan terhadap Peningkatkan Daya Saing Industri Batik "Kampoeng Batik Laweyan" Solo?

\section{TUJUAN PENELITIAN}

1. Menganalisis pengaruh Batik Laweyan dengan diferensiasinya terhadap Peningkatan Daya Saing Industri Batik "Kampoeng Batik Laweyan" Solo.

2. Menganalisis pengaruh Penetapan Brand "Kampoeng Batik Laweyan" terhadap Peningkatan Daya Saing Industri Batik "Kampoeng Batik Laweyan" Solo.

3. Menganalisis pengaruh Brand

"Kampoeng Batik Laweyan" dalam Menguatkan Batik Laweyan untuk Peningkatkan Daya Saing Industri Batik "Kampoeng Batik Laweyan" Solo.

\section{KERANGKA PEMIKIRAN}

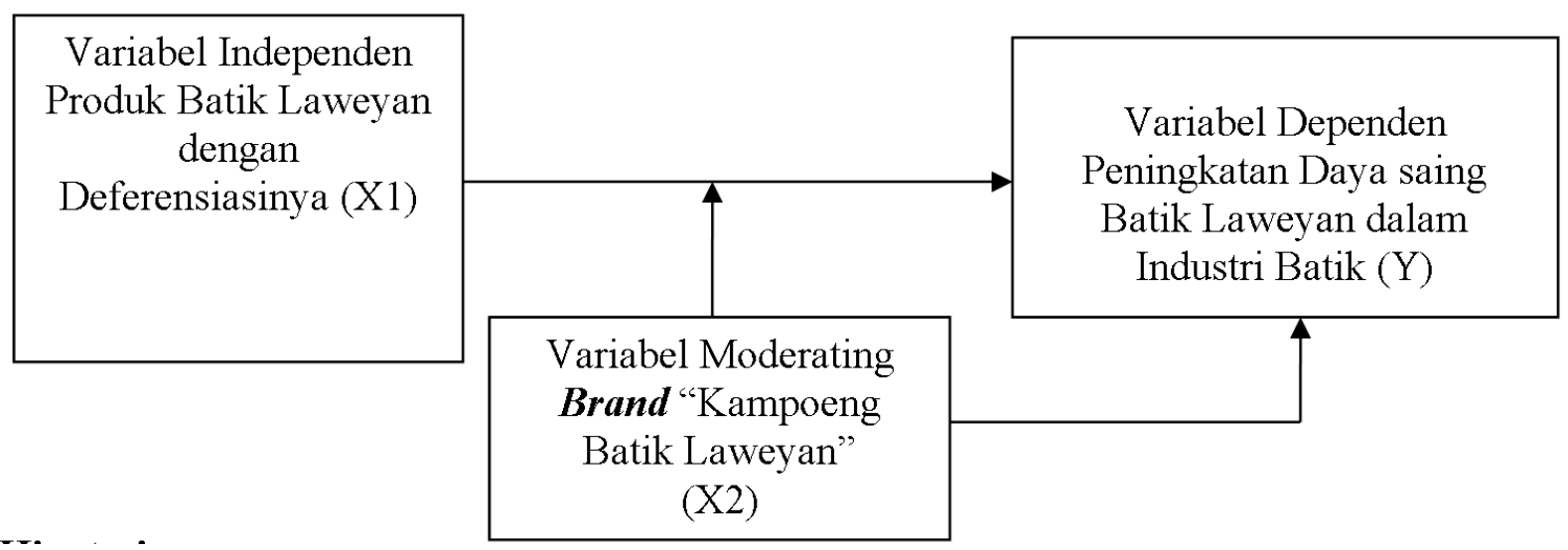

\section{Hipotesis :}

1. Awalnya batik Laweyan didominasi oleh disain batik tradisional. Dengan adanya "Kampoeng Batik Laweyan", motif disain jauh berkembang, permintaan pasar dan usaha memaksa menampilkan karya unik dan khas di masing-masing gerai (khususnya untuk menarik wisatawan), munculah motif modern dan abstrak. (Indah N R, 2013). Diversifikasi produk, awalnya terbatas pada produk sandang, berkembang dan muncul produk batik bentuk lain seperti kerajinan tangan (tas, dompet dan perlengkapan pakaian), perlengkapan rumah tangga (household), batik kayu, batik kaca. Untuk menjaga khas dan uniknya produksi batik di Laweyan menggunakan teknologi tradisional, untuk mensiasati permintaan pasar yang semakin besar dibuat batik cap dan tulis, dan positioning dengan differensiasi (Diana Elma, 2012) maka dikemukakan hipotesis pertama: Produk Batik Laweyan dengan Deferensiasinya Signifikan Mempengaruhi Peningkatan Daya Saing Penjualan Batik pada Industri Batik "Kampoeng Batik Laweyan" di Kota Solo.

2. Mahendra W (Diakses 21 Maret 2015) perlunya Pemda turut serta meningkatkan kualitas dalam manajemen produksi dan pengetahuan-ketrampilan. Andri Satrio Pratomo, et 
al (2006), Kampung Batik Laweyan memenuhi kriteria sebagai kampung tradisional perkotaan dengan karakter ketradisionalan yang kuat, ditetapkannya sebagai "Kampoeng Batik Laweyan" sangat baik apalagi setelah adanya pembajakan dan pematenan batik Indonesia oleh Malaysia, kewajiban berbusana batik bagi pegawai negeri juga meningkatkan penjualan batik.(Atiqa Sabardila,et al, 2008). Pembeli Batik Laweyan selain membeli batik, juga bisa menikmati situs budaya Kampoeng Laweyan atau belajar seni membatik. (Ridho Maruli dan Mukti Ali, 2013). Dikemukakan hipotesis kedua: Penetapan Brand "Kampoeng Batik Laweyan" Signifikan Berpengaruh terhadap Peningkatan Daya Saing Penjualan Batik pada Industri Batik Kampoeng Batik Laweyan di Kota Solo.

3. Sebagian besar produk eskpor batik Laweyan masih merupakan produk tanpa merk, sehingga belum secara maksimal peningkatan daya saing produknya untuk masuk pasar internasional dengan merk lokal. Dengan Brand Kampoeng Batik Laweyan, menjadikan adanya BatikMark. yang menunjukkan identitas dan ciri batik buatan Indonesia yang terdiri dari 3 jenis yaitu batik tulis, batik cap dan batik kombinasi. Terdapatnya Website "Kampung Batik Laweyan", menjadikan dikenal secara global. (Siti Rahayu, et al, 2013). maka hipotesis ketiga Brand "Kampoeng Batik Laweyan" Signifikan Menguatkan Produk Batik Laweyan dalam Peningkatkan Daya Saing Penjualan Batik pada Industri Batik "Kampoeng Batik Laweyan" Solo.

\section{HASIL PENELITIAN}

\section{Data}

Data yang digunakan dalam penelitian ini adalah data primer yang diperoleh dengan memberikan kuesioner kepada responden yaitu pengusaha di Kampoeng Batik Laweyan, sebanyak 56 responden sedangkan jumlah data representative sebesar 55 responden.

\section{Metode Analisis}

\section{Uji Validitas}
a. Uji Validitas Variabel Produk Batik Laweyan (X1)

Tabel I

Uji Validitas Variabel Produk Batik Laweyan (X1)

\begin{tabular}{cccc}
\hline Item Pertanyaan & Kriteria Signifikansi $\boldsymbol{\alpha}=\mathbf{0 , 0 5}$ & Hasil & Keterangan \\
\hline X1-1 & 0,05 & 0,000 & Valid \\
X1-2 & 0,05 & 0,000 & Valid \\
X1-3 & 0,05 & 0,000 & Valid \\
X1-4 & 0,05 & 0,000 & Valid \\
X1-5 & 0,05 & 0,000 & Valid \\
\hline
\end{tabular}

Sumber: Data Primer diolah

Dari tabel di atas dapat dilihat bahwa semua item pertanyaan untuk variabel Produk Batik Laweyan adalah Valid, dengan signifikansi

$$
0,000<0,05 \text {. }
$$

b. Uji Validitas Variabel Brand Kampoeng Batik Laweyan (X2)

Tabel II

Uji Validitas Variabel Brand Kampoeng Batik Laweyan (X2)

\begin{tabular}{cccc}
\hline Item Pertanyaan & Kriteria Signifikansi $\boldsymbol{\alpha}=\mathbf{0 , 0 5}$ & Hasil & Keterangan \\
\hline X2-1 & 0,05 & 0,000 & Valid \\
X2-2 & 0,05 & 0,000 & Valid \\
X2-3 & 0,05 & 0,000 & Valid \\
X2-4 & 0,05 & 0,000 & Valid \\
X2-5 & 0,05 & 0,000 & Valid \\
\hline
\end{tabular}

Sumber: Data Primer diolah 
Dari tabel di atas dapat dilihat bahwa semua item pertanyaan untuk variabel Brand Kampung Batik Laweyan adalah Valid, dengan signifikansi $0,000<0,05$.

c. Uji Validitas Variabel Daya Saing Industri Batik (Y)

Tabel III

Uji Validitas Variabel Daya Saing Industri Batik (Y)

\begin{tabular}{cccccccc}
\hline $\begin{array}{c}\text { Item } \\
\text { Pertanyaan }\end{array}$ & $\begin{array}{c}\text { Kriteria } \\
\text { Signifikansi } \\
\boldsymbol{\alpha = \mathbf { 0 , 0 5 }}\end{array}$ & Hasil & Keterangan & $\begin{array}{c}\text { Item } \\
\text { Pertanyaan }\end{array}$ & $\begin{array}{c}\text { Kriteria } \\
\text { Signifikansi } \\
\boldsymbol{\alpha}=\mathbf{0 , 0 5}\end{array}$ & Hasil & Keterangan \\
\hline Y-1 & $\mathbf{0 , 0 5}$ & $\mathbf{0 , 0 0 0}$ & Valid & $\mathbf{Y - 5}$ & $\mathbf{0 , 0 5}$ & $\mathbf{0 , 0 0 0}$ & Valid \\
Y-2 & $\mathbf{0 , 0 5}$ & $\mathbf{0 , 0 0 0}$ & Valid & Y-6 & $\mathbf{0 , 0 5}$ & $\mathbf{0 , 0 0 0}$ & Valid \\
Y-3 & $\mathbf{0 , 0 5}$ & $\mathbf{0 , 0 0 0}$ & Valid & Y-7 & $\mathbf{0 , 0 5}$ & $\mathbf{0 , 0 0 0}$ & Valid \\
Y-4 & $\mathbf{0 , 0 5}$ & $\mathbf{0 , 0 0 0}$ & Valid & Y-8 & $\mathbf{0 , 0 5}$ & $\mathbf{0 , 0 0 0}$ & Valid \\
\hline
\end{tabular}

Sumber: Data Primer diolah

Dari tabel di atas dapat dilihat bahwa semua item pertanyaan untuk

Variabel Daya Saing Industri Batik adalah Valid, dengan signifikansi $0,000<0,05$.

\section{Uji Reliabilitas}

Tabel IV

Uji Reliabilitas

\begin{tabular}{|l|c|c|c|}
\hline \multicolumn{1}{|c|}{ Variabel } & Kriteria Signifikan Cronbach $\boldsymbol{\alpha}=\mathbf{0 , 6 0}$ & Hasil & Keterangan \\
\hline Produk Batik Laweyan (X1) & 0,05 & 0,882 & Reliabel \\
Brand Kampoeng Batik Laweyan (X2) & 0,05 & 0,883 & Reliabel \\
Daya Saing Industri Batik (Y) & 0,05 & 0,942 & Reliabel \\
\hline
\end{tabular}

Sumber: Data Primer Diolah

Dari tabel di atas dapat dilihat bahwa semua item pertanyaan untuk semua variabel adalah reliabel karena nilai cornbach alpa $>0,60$.

\section{Uji Asumsi Klasik}

a. Uji Multikolinearitas

Tabel V

Uji Multikolinieritas

\begin{tabular}{|l|r|r|}
\hline \multicolumn{2}{|c|}{ Coefficients $^{\text {a }}$} & \multicolumn{2}{c|}{ Collinearity Statistics $^{\text {Model }}$} & Tolerance & VIF \\
\cline { 2 - 3 } 1 X1 (Brodyk Batik Laweyan) & .911 .098 & 1.098 \\
\hline
\end{tabular}

Dari tabel di atas, nilai tolerance untuk variabel $\mathrm{X} 1, \mathrm{X} 2,>0,10$ dan nilai VIF $<10$, maka tidak terjadi multikolinearitas.

b. Uji Autokorelasi

Tabel VI

Uji Autokorelasi

\begin{tabular}{lr}
\hline \multicolumn{2}{c}{ Runs Test } \\
\hline \multicolumn{1}{c}{ Unstandardized Residual } \\
\hline Test Value $^{\text {a }}$ & .10053 \\
Cases $<$ Test Value & 27 \\
\hline
\end{tabular}




\begin{tabular}{lr}
\hline \multicolumn{2}{c}{ Runs Test } \\
\hline \multicolumn{2}{c}{ Unstandardized Residual } \\
\hline Cases $>=$ Test Value & 28 \\
Total Cases & 55 \\
Number of Runs & 28 \\
Z & -.134 \\
Asymp. Sig. (2-tailed) & .894 \\
a. Median & \\
\hline
\end{tabular}

Dari tabel di atas Runs Test diperoleh $\rho$ value $0,894>0,05$ maka lolos autokorelasi. c. Uji Heteroskesdastisitas

Tabel VII

Uji Heteroskedastisitas

\begin{tabular}{|c|c|c|c|c|c|c|}
\hline \multicolumn{7}{|c|}{ Coefficients $^{\mathrm{a}}$} \\
\hline & \multirow[t]{2}{*}{ Model } & \multicolumn{2}{|c|}{$\begin{array}{c}\text { Unstandardized } \\
\text { Coefficients }\end{array}$} & \multirow{2}{*}{$\begin{array}{c}\begin{array}{c}\text { Standardized } \\
\text { Coefficients }\end{array} \\
\text { Beta }\end{array}$} & \multirow[t]{2}{*}{$\mathbf{t}$} & \multirow[t]{2}{*}{ Sig. } \\
\hline & & B & Std. Error & & & \\
\hline \multirow{3}{*}{1} & (Constant) & 4.286 & 1.776 & & 2.414 & .019 \\
\hline & X1 (Produk Batik Laweyan) & .004 & .068 & .008 & .054 & .957 \\
\hline & X2 (Brand Kampoeng Batik Laweyan) & -.095 & .078 & -.174 & -1.212 & .231 \\
\hline
\end{tabular}

Uji Gleijser diperoleh $\rho$ value variabel X1, X2 >0,05 maka lolos heteroskesdastisitas d. Uji Normalitas

Tabel VIII

Uji Normalitas

\begin{tabular}{llr}
\hline \multicolumn{3}{c}{ One-Sample Kolmogorov-Smirnov Test } \\
\hline $\mathrm{N}$ & & Unstandardized Residual \\
\hline \multirow{2}{*}{ Normal Parameters ${ }^{\mathrm{a}, \mathrm{b}}$} & Mean & 55 \\
& Std. Deviation & .0000000 \\
& Absolute & 3.11768673 \\
Most Extreme Differences & Positive & .088 \\
& Negative & .051 \\
Kolmogorov-Smirnov Z & & -.088 \\
Asymp. Sig. (2-tailed) & & .651 \\
\hline a. Test distribution is Normal. & .791 \\
\hline b. Calculated from data. & \\
\hline
\end{tabular}

Uji Kolmogorov-Smirnov diperoleh $\rho$ value $0,791>0,05$, maka data berdistribusi normal.

\section{Analisis Data}

a. Uji -t. (Uji Signifikan Parsial)

Uji signifikansi Pengaruh Variabel

Produk Batik Laweyan (X1) dan
Brand Kampoeng Batik Laweyan (X2) terhadap Daya Saing Industri Batik (Y) 
Tabel IX

Signifikansi Pengaruh X1 Dan X2 Terhadap Y

Coefficients $^{\mathrm{a}}$

\begin{tabular}{|c|c|c|c|c|c|c|}
\hline & \multirow{2}{*}{ Model } & \multicolumn{2}{|c|}{ Unstandardized Coefficients } & \multirow{2}{*}{$\begin{array}{c}\text { Standardized Coefficients } \\
\text { Beta } \\
\end{array}$} & \multirow{2}{*}{$t$} & \multirow{2}{*}{ Sig. } \\
\hline & & B & Std. Error & & & \\
\hline \multirow{3}{*}{1} & (Constant) & -1.044 & 2.897 & & -.360 & .720 \\
\hline & $\mathrm{X} 1$ & .708 & .110 & .484 & 6.413 & .000 \\
\hline & X2 & .968 & . 127 & .574 & 7.603 & .000 \\
\hline
\end{tabular}

Dari Tabel diatas diperoleh nilai $\rho$ value pengaruh variabel Produk Batik Laweyan (X1) terhadap Peningkatan Pendapatan Pedagang (Y) sebesar $0,000<0,05$, maka Ho ditolak, berarti variabel Produk Batik Laweyan (X1) berpengaruh signifikan terhadap Daya Saing Industri Batik (Y). Nilai $\rho$ value pengaruh variabel Brand Kampoeng Batik Laweyan (X2) terhadap Peningkatan Pendapatan Pedagang (Y) sebesar $0,000<0,05$, maka Ho ditolak, berarti variabel Brand Kampoeng Batik Laweyan (X2) berpengaruh signifikan terhadap Daya Saing Industri Batik (Y).

b. Regresi Linear Berganda antara Variabel Produk Batik Laweyan (X1), Brand Kampoeng Batik Laweyan (X2) terhadap Daya Saing Industri Batik (Y)

Tabel X

Koefisien Regresi Linier Berganda

\begin{tabular}{|c|c|c|c|c|c|c|}
\hline \multicolumn{7}{|c|}{ Coefficients $^{\mathbf{a}}$} \\
\hline & \multirow[t]{2}{*}{ Model } & \multicolumn{2}{|c|}{$\begin{array}{l}\text { Unstandardized } \\
\text { Coefficients }\end{array}$} & \multirow{2}{*}{$\begin{array}{c}\begin{array}{c}\text { Standardized } \\
\text { Coefficients }\end{array} \\
\text { Beta } \\
\end{array}$} & \multirow[t]{2}{*}{$\mathbf{t}$} & \multirow[t]{2}{*}{ Sig. } \\
\hline & & B & Std. Error & & & \\
\hline \multirow{3}{*}{1} & (Constant) & -1.044 & 2.897 & & -.360 & .720 \\
\hline & X1 (Produk Batik laweyan) & .708 & .110 & .484 & 6.413 & .000 \\
\hline & X2 (Brand Kampoeng Batik Laweyan) & .968 & .127 & .574 & 7.603 & .000 \\
\hline
\end{tabular}

a. Dependent Variable: Y

Dari tabel diatas maka persamaan regresi liner berganda adalah :

$\mathrm{Y}=-1,044+0,708 \mathrm{X} 1+0,968 \mathrm{X} 2$ $+\mathrm{e}$

Interpretasi persamaan regresi tersebut adalah :

a =- 0,143 bahwa Daya Saing Industri Batik adalah negative artinya bila tidak ada Produk Batik Laweyan (X1) dan tidak dilakukan Branding Kampoeng Batik Laweyan maka Daya Saing Batik Laweyan pada Industri Batik adalah negative. b1 $=0,708$ artinya bahwa dengan adanya Produk Batik Laweyan berpengaruh positif terhadap Daya Saing Batik Laweyan dalam Industri Batik dengan asumsi tidak dilakukan Branding Kampoeng Batik Laweyan .

b2 $=0,968$ artinya bahwa dengan adanya Branding Kampoeng Batik laweyan berpengaruh positif terhadap Daya Saing Batik laweyan dalam Industri Batik dengan asumsi tidak ada Produk Batik Laweyan . 
Dari tabel tersebut diatas karena koefisien pengaruh variabel Brand Kampoeng Batik Laweyan (X2) sebesar 0,968 lebih besar dari koefisien pengaruh variabel Produk Batik Laweyan (X1) maka variabel Brand Kampoeng Batik Laweyan dominan mempengaruhi Daya Saing Batik Laweyan dalam Industri Batik. c. Analisis Regresi dengan Variabel Moderating

Uji Signifikansi Pengaruh Variabel Produk Batik Laweyan (X1) Terhadap Daya Saing Industri Batik (Y) dengan Brand kampoeng Batik Laweyan (X2) sebagai Variabel Moderasi (Uji Selisih Mutlak)

Tabel XI

Signifikansi Pengaruh X1 Terhadap Y Dengan X2 Sebagai Modersi

\begin{tabular}{|c|c|c|c|c|c|c|c|}
\hline & \multicolumn{7}{|c|}{ Coefficients $^{a}$} \\
\hline & \multirow{2}{*}{ Model } & \multicolumn{2}{|c|}{ Unstandardized Coefficients } & \multicolumn{2}{|c|}{ Standardized Coefficients } & \multirow{2}{*}{$\mathbf{t}$} & \multirow{2}{*}{ Sig. } \\
\hline & & B & Std. Error & Beta & & & \\
\hline \multirow{4}{*}{1} & (Constant) & 32.254 & .722 & & & 44.673 & .000 \\
\hline & Zscore(X1) & 2.947 & .454 & & .491 & 6.490 & .000 \\
\hline & Zscore(X2) & 3.525 & .459 & & .588 & 7.684 & .000 \\
\hline & ABSZX1_ZX2 & .660 & .621 & & .078 & 1.063 & .029 \\
\hline
\end{tabular}

a. Dependent Variable: Y

Nilai $\rho$ value pengaruh variabel Produk Batik Laweyan (X1) terhadap Daya Saing Industri Batik (Y) yang dimoderasi oleh variabel Brand Kampoeng Batik Laweyan (X2) sebesar 0,029<0,05, maka Ho ditolak, berarti variabel Brand Kampoeng Batik laweyan (X2) signifikan memoderasi pengaruh variabel Produk Batik Laweyan terhadap Daya Saing Industri Batik (Y).
Untuk menentukan apakah variabel Brand Kampoeng Batik laweyan memperkuat atau memperlemah pengaruh variabel Produk batik Laweyan terhadap Peningkatan Daya Saing Batik laweyan dalam Industri Batik dilakukan dengan membandingkan Adjusted $\mathrm{R}^{2}$ sebelum memasukan variabel moderasi dengan sesudah memasukan variabel moderasi. Hasilnya terlihat dalam dua tabel di bawah ini.

Tabel XII

Adjusted R Square X1 Terhadap Y Sebelum Dimoderasi X2

\begin{tabular}{|c|c|c|c|c|c|c|c|c|c|}
\hline \multicolumn{10}{|c|}{ Model Summary } \\
\hline \multirow[b]{2}{*}{ Model } & \multirow[b]{2}{*}{$\mathrm{R}$} & \multirow[b]{2}{*}{ R Square } & \multirow[b]{2}{*}{$\begin{array}{l}\text { Adjusted R } \\
\text { Square }\end{array}$} & \multirow[b]{2}{*}{$\begin{array}{l}\text { Std. Error of } \\
\text { the Estimate }\end{array}$} & \multicolumn{5}{|c|}{ Change Statistics } \\
\hline & & & & & $\begin{array}{l}\text { R Square } \\
\text { Change }\end{array}$ & F Change & df1 & df2 & $\begin{array}{c}\text { Sig. F } \\
\text { Change }\end{array}$ \\
\hline 1 & $.854^{\mathrm{a}}$ & .730 & .720 & 3.177 & .730 & 70.302 & 2 & 52 & .000 \\
\hline
\end{tabular}

Tabel XIII

Adjusted R Square X1 terhadap Y Sesudah Dimoderasi X2

\begin{tabular}{|c|c|c|c|c|c|c|c|c|c|}
\hline \multicolumn{10}{|c|}{ Model Summary } \\
\hline \multirow[b]{2}{*}{ Model } & \multirow[b]{2}{*}{$\mathbf{R}$} & \multirow[b]{2}{*}{$\begin{array}{c}\text { R } \\
\text { Square }\end{array}$} & \multirow[b]{2}{*}{$\begin{array}{l}\text { Adjusted R } \\
\text { Square }\end{array}$} & \multirow[b]{2}{*}{$\begin{array}{l}\text { Std. Error of } \\
\text { the Estimate }\end{array}$} & \multicolumn{5}{|c|}{ Change Statistics } \\
\hline & & & & & $\begin{array}{l}\text { R Square } \\
\text { Change }\end{array}$ & $\begin{array}{c}\text { F } \\
\text { Change }\end{array}$ & df1 & df2 & $\begin{array}{c}\text { Sig. F } \\
\text { Change }\end{array}$ \\
\hline 1 & $.858^{\mathrm{a}}$ & .736 & .723 & 3.173 & .736 & 47.362 & 3 & 51 & .000 \\
\hline \multicolumn{10}{|c|}{ a. Predictors: (Constant), ABSZX1_ZX2, Zscore(X1), Zscore(X2) } \\
\hline
\end{tabular}


Dari kedua Tabel diketahui bahwa Adjusted $\mathrm{R}^{2}$ pengaruh variabel Produk Batik Laweyan terhadap Daya Saing Industri Batik sebelum dimasukkan variabel moderasi sebesar 0,720 atau $72 \%$, sedangkan Adjusted $\mathrm{R}^{2}$ sesudah dimasukkan variabel moderasi sebesar 0,723 atau $72,3 \%$, lebih besar dari Adjusted sebelum dimasukkan variabel moderasi. Dengan demikian variabel Brand kampoeng Batik laweyan terbukti memperkuat pengaruh Produk Batik Laweyan terhadap Daya Saing Batik Laweyan dalam Industri Batik.

d. Koefisien Determinasi $\left(\mathrm{R}^{2}\right)$

Koefisien Determinasi diperoleh dari Adjusted $\mathrm{R}^{2}$ sebesar 0,723 atau $72,3,8 \%$, artinya bahwa sumbangan pengaruh Variabel Produk Batik Laweyan terhadap Daya saing Batik Laweyan dalam Industri Batik yang dimoderasi oleh Brand Kampoeng Batik Laweyan sebesar 72,3 \% sedang sisanya $14,2 \%$ dipengaruhi oleh variabel lain yang tidak diteliti.

\section{KESIMPULAN}

1. Hasil uji validitas menunjukkan bahwa semua item pertanyaan baik dari variabel Produk Batik laweyan, variabel Brand kampung Batik Laweyan dan Daya Saing Batik Laweyan dalam Industri Batik semua valid karena nilai signifikansi < 0,05 .

2. Uji Reliabilitas menunjukkan bahwa semua item pertanyaan baik dari variabel Produk Batik laweyan, variabel Brand kampung Batik Laweyan dan Daya Saing Batik Laweyan dalam Industri Batik semua reliable karena nila Cornbach alpa $>0,6$.

3. Uji Asumsi Klasik menunjukkan bahwa lolos untuk semua uji asumsi klasik baik uji multikolinearitas, uji autokorelasi, uji heteroskedastisitas dan uji normalitas.

4. Dari uji signifikansi t nilai $\rho$ value pengaruh variabel Distribusi Produk Batik laweyan (X1) terhadap Daya Saing batik Laweyan dalam Industri Batik (Y) sebesar $0,000<0,05$, maka Ho ditolak, berarti variabel Produk Batik Laweyan (X1) berpengaruh signifikan terhadap Daya Saing Batik Laweyan dalam Industri Batik (Y), dengan demikian hipotesis yang menyatakan bahwa variabel Produk Batik Laweyan (X1) berpengaruh signifikan terhadap Daya Saing Batik Laweyan dalam Industri Batik (Y) terbukti kebenarannya.

5. Dari uji signifikansi t nilai $\rho$ value pengaruh variabel Brand kampoeng batik Laweyan (X2) terhadap Daya Saing Batik Laweyan dalam Industri Batik (Y) sebesar $0,000<0,05$, maka Ho ditolak, dengan demikian hipotesis yang menyatakan bahwa variabel Brand kampoeng batik Laweyan (X2) berpengaruh signifikan terhadap Daya Saing Batik Laweyan dalam Industri Batik (Y) terbukti kebenarannya.

6. Dari uji signifikansi t nilai $\rho$ value pengaruh variabel Produk Batik Laweyan (X1) terhadap Daya Saing Batik Laweyan dalam Industri Batik (Y) yang dimoderasi variabel Brand kampoeng Batik Laweyan (X2) sebesar 0,023<0,05, maka Ho ditolak, berarti pengaruh Variabel Brand Kampung Batik Laweyan memoderasi pengaruh variabel Produk Batik Laweyan (X1) terhadap Daya Saing Batik Laweyan dalam Industri Batik (Y), dengan demikian hipotesis yang menyatakan bahwa Variabel Brand Kampung Batik Laweyan memoderasi pengaruh variabel Produk Batik Laweyan (X1) terhadap Daya Saing Batik Laweyan dalam Industri Batik (Y) terbukti kebenarannya.

\section{DAFTAR PUSTAKA}

Andri Satrio Pratomo, et al , 2006, Pelestarian Kawasan Kampung Batik Laweyan Kota Surakarta, DIMENSI TEKNIK ARSITEKTUR Vol.34, No. 2, Desember 2006: 93 - 105

Atiqa Sabardila, Markhamah, Djandjang Purwo Sejati, Agus Budi Wahyudi, 2008, Keterampilan 
Membatik Sebagai Model Pembelajaran Ekstrakurikular Siswa SMP Di Surakarta, Jurnal Penelitian Humaniora, Volume 9, No 1, Tahun 2008, Halaman 54-70)

Aviarini Indrati, Rina Sugiarti, Yusye Nilawati, 2011, Pengembangan Dokumentasi Elektronik Batik Jawa, Bali dan Madura Berbasis Web, Penelitian Hibah DIKTI

Baidi, 2006, Pertumbuhan Pengusaha Batik Laweyan Surakarta, Suatu studi Sejarah Sosial Ekonomi, Jurnal Bahasa dan Seni, Tahun 34, No. 2, Agustus 2006 hal 241-253

Berta Bekti Retnawati, A. Eva Maria Soekesi ,2010, Model Supply Chain Produk Usaha Kecil (studi Kasus Pada Kampoeng Batik Laweyan Surakarta), Semarang:UNIKA Soegijapranata

Boeke, J H dan D H Burger. 1973. Ekonomi Dualistik : Dialog Antara Boeke dan Burger. Jakarta: Bharata

Diana Elma Widyaningrum, 2012, Strategi Pemasaran Kampung Batik Laweyan Solo, Thesis, Universitas Indonesia, Jakarta

Geertz, Cllifford.1973. The Interpretation of Culture. New York: Basic Book.

Imam Gozali, 2013, Aplikasi Analisis Multivariate dengan Program SPSS, Badan Penerbit UNDIP, Semarang

Indah Nur Rahmawati. 2013, Dampak Event Sepak Bola Dunia Terhadap Inovasi Produk Dan Pemasaran Pada Home Industry Di Kampung Batik Laweyan Solo (Sebuah Analisis Tentang Sport Industry). Skripsi Jurusan Ilmu Keolahragaan. Fakultas Ilmu Keolahragaan. Universitas Negeri Semarang.

Irvan Indra Savira Putra, 2009, Analisis Faktor-faktor yang Mempengaruhi Kinerja Industri Kerajinan di Indonesia, Repository.ipb.ac.id

Kotler, Philip, 2009, Manajemen Pemasaran, Analisis, Perencanaan, Implementasi dan Kontrol, Jilid I dan Jilid II, Alih bahasa Imam Nurmawan, Edisi Ketiga, PT. Prehalindo, Jakarta.

Mahendra Wijaya, Pola Hubungan Produksi Industri Rumah Tangga Batik Tulis dengan Pabrikan Batik Cap-tulis dan Manufaktur Batik Printing-tulis, Jurnal ILMU dan BUDAYA, Halaman 2411-2422, Diakses 20 Maret 2015

Mowen, John C, dan Minor, Michael, 2002, Perilaku Konsumen, Alih Bahasa Dwi Kartini Yahya, Erlangga, Jakarta.

Nurhadiantomo,2004. Konflik Sosial Pri dan Non Pri dan Hukum Keadilan Sosial. Surakarta: Muhammadiyah University Press.

Ratih Kusumandari, Rina Kurniati, 2011, Kajian Karakteristik Kampung Batik Laweyan Sebagai Kampung Tradisional Di Kota Solo, Diponegoro University | Institutional Repository (UNDIP-IR)

Retno Dewanti, Ina Melati, Freddy Simbolon, 2013, Pengembangan Model Daya Saing UMKM Batik Melalui ECS, Binus Business Review, Vol 4 No 1, Mei 2013, hal 41-57

Ridho Maruli S dan Muhammad Mukti Ali,2013, Proses Inovasi Pada Klaster Kampoeng Batik Laweyan Kota Surakarta, Jurnal Teknik PWK, Vol 2, No 2,tahun 2013, hal 198-208

Sidiq Maulana, Nurini, 2010, Kajian Kesiapan Kampoeng Batik Laweyan Solo sebagai Kawasan Wisata Budaya, Jurnal Tataloka, Jurnal Ilmiah Perencanaan Wilayah dan Kota, vol 12, No 4, tahun 2010, hal 221-231.

Siti Rahayu Binarsih, Endang Siti Rahayu, Slamet Riyadi Bisri, Muladi Wibowo, 2013, Bisnis 
Internasional Bagi Pengusaha di Kampung Batik Laweyan, Prosiding Seminar Nasional Menuju Masyarakat Madani dan Lestari, ISBN: 978-979-98438-8-3, halaman 101-111

Soedarmono. 1987. Munculnya Kelompok Saudagar Batik di Laweyan Pada Awal Abad XX Yoyakarta: Fakultas Pasca Sarjana Universitas Gadjah Mada.

Vicka Tamaya, Susi Sulandari, Dyah Lituhayu, Optimalisasi Kampung Batik dalam Mengembangkan Industri Batik Semarang di Kota Semarang, Skripsi Jurusan Administrasi Publik, FISIP, UNDIP, Semarang. Diakses pada 31 Maret 2015.

http://www.kampoenglaweyan.com/id

http://id.wikipedia.org 